\title{
Dead Space to Tidal Volume Ratio Is Associated With Higher Postextubation Support in Children
}

\author{
Jonathan A Gehlbach, Andrew G Miller, Christoph P Hornik, and Ira M Cheifetz
}

\begin{abstract}
BACKGROUND: Extubation failure is associated with increased duration of mechanical ventilation, length of hospital stay, and mortality. An elevated dead-space-to-tidal-volume ratio $\left(V_{D} / V_{T}\right)$ has been proposed as a predictor of successful extubation in children. We hypothesized that a higher $V_{D} / V_{T}$ value would be associated with extubation failure and higher postextubation respiratory support. METHODS: This was a prospective, observational, cohort study. All subjects were $<18 \mathrm{y}$ old and were extubated in the pediatric multidisciplinary ICU or the cardiac ICU at an academic medical center from June 2016 through March 2017. Using arterial blood gas analysis and mainstream volumetric capnography, daily $V_{D} / V_{T}$ measurements were obtained on intubated subjects using an automated algorithm. Respiratory support upon extubation was based on the clinical team's judgment and defined as low (ie, room air or nasal cannula) or high (ie, high-flow nasal cannula, CPAP, or bi-level positive airway pressure). Subjects were monitored for $48 \mathrm{~h}$ after extubation for escalation in respiratory support and need for re-intubation. RESULTS: Of 189 subjects included in the analysis, 166 were successfully extubated and 23 (12\%) required re-intubation. There was no significant difference in final $V_{D} / V_{T}$ between those who extubated successfully and those who failed extubation, with a median $V_{D} / V_{T}$ of 0.28 (interquartile range $[\mathrm{IQR}] \mathrm{0.20-0.37)}$ vs 0.29 (IQR $0.21-0.33)$, respectively $(P=.87)$. Those who received a high level of support upon extubation had a higher $V_{D} / V_{T}$ than those who received a low level of support, with a median of 0.32 (IQR 0.23-0.39) vs 0.25 (IQR 0.16-0.30), respectively $(P<.001)$. This association remained significant when controlling for age, duration of intubation, and cyanotic congenital heart disease (odds ratio 1.63, 95\% CI 1.18-2.24), CONCLUSIONS: There was no significant relationship between $V_{D} / V_{T}$ and extubation success, although $\mathbf{V}_{\mathrm{D}} / \mathbf{V}_{\mathrm{T}}$ was associated with the level of respiratory support provided following extubation. Further studies should investigate whether the use of $V_{D} / V_{T}$ can help reduce extubation failure rates with varying levels of postextubation respiratory support. Key words: dead space; respiratory failure; extubation readiness; mechanical ventilation; critical care; pediatric; gas exchange. [Respir Care 2020;65(11):1721-1729. (C) 2020 Daedalus Enterprises]
\end{abstract}

\section{Introduction}

Extubation failure occurs in $4-14 \%$ of mechanically ventilated pediatric patients. ${ }^{1-7}$ The need for re-intubation has been associated with increased duration of mechanical

Dr Gehlbach is affiliated with the Department of Pediatrics, Division of Pediatric Critical Care Medicine, The University of Illinois College of Medicine, Peoria, Illinois. Mr Miller and Dr Cheifetz are affiliated with Respiratory Care Services, Duke University Medical Center, Durham, North Carolina. Drs Hornik and Cheifetz are affiliated with the Department of Pediatrics, Division of Pediatric Critical Care Medicine, Duke Children's Hospital, Durham, North Carolina. ventilation, length of hospital and ICU stay, and mortality. ${ }^{2,4,6}$ Currently, there is no one tool that reliably predicts successful extubation in children. Validated extubation tools that quantify pulmonary disease may help reduce the

Dr Gehlbach presented a version of this paper at the American Thoracic Society International Conference, held May 21, 2017, in Washington, DC.

Dr Cheifetz has disclosed relationships with Philips Respironics and Upto-Date. Mr Miller has disclosed a relationship with Ventec Life Systems. Drs Gehlbach and Hornik have disclosed no conflicts of interest. 


\section{$\mathrm{V}_{\mathrm{D}} / \mathrm{V}_{\mathrm{T}}$ AND Postextubation Respiratory SuPPORT In CHILDRen}

incidence of failed extubation and thus may limit morbidity and potentially mortality. Furthermore, improved ability to predict those at risk for extubation failure may influence the choice of postextubation respiratory support.

One such proposed tool is the ratio of dead space to tidal volume $\left(\mathrm{V}_{\mathrm{D}} / \mathrm{V}_{\mathrm{T}}\right)$. Physiologic dead space represents the portion of the respiratory tract that does not participate in gas exchange. Normal $V_{D} / V_{T}$ ranges from 0.25 to 0.4 , whereas $V_{D} / V_{T}>0.4$ (ie, more dead space) suggests pulmonary pathology. A quantitative assessment of physiologic dead space, $V_{D} / V_{T}$ has been reported to have utility in predicting extubation failure in adults, ${ }^{8,9}$ as well as prognosticating in $\mathrm{ARDS}^{10-13}$ and measuring the impact of bronchodilators in COPD. ${ }^{14}$ In children, $\mathrm{V}_{\mathrm{D}} / \mathrm{V}_{\mathrm{T}}$ has been used as a marker of severity of lung disease ${ }^{15,16}$ and as a method to trend gas exchange in the lungs of neonates requiring extracorporeal membranous oxygenation, ${ }^{17}$ and it is associated with prolonged duration of mechanical ventilation. ${ }^{18}$ $\mathrm{V}_{\mathrm{D}} / \mathrm{V}_{\mathrm{T}}$ has been studied as a predictor of successful extubation in children with mixed results. Hubble et $\mathrm{al}^{19}$ and Riou et $\mathrm{al}^{20}$ each reported that a higher $\mathrm{V}_{\mathrm{D}} / \mathrm{V}_{\mathrm{T}}(>0.65$ and $>$ 0.55 , respectively) was associated with extubation failure, whereas Bousso et $\mathrm{al}^{21}$ failed to find such an association. Of these, only the study by Riou et $\mathrm{al}^{20}$ was published within the past $10 \mathrm{y}$, during which time there have been significant advancements in respiratory management in the ICU. More recently, Devor et $\mathrm{al}^{22}$ noted an association between extubation failure and $\mathrm{V}_{\mathrm{D}} / \mathrm{V}_{\mathrm{T}}>0.5$ in children who underwent cardiac surgery with 2-ventricle repair, but not in those with single-ventricle physiology.

The purpose of this study was to add to the existing literature on $\mathrm{V}_{\mathrm{D}} / \mathrm{V}_{\mathrm{T}}$ as a potential risk factor for extubation failure in children after the widespread adoption of noninvasive respiratory support in the ICU. Most studies to date were published prior to the introduction and adoption of high-flow nasal cannula (HFNC) and noninvasive ventilation. We hypothesized that elevated $\mathrm{V}_{\mathrm{D}} / \mathrm{V}_{\mathrm{T}}$ would be associated with risk for extubation failure. We also hypothesized, as a secondary outcome, that $\mathrm{V}_{\mathrm{D}} / \mathrm{V}_{\mathrm{T}}$ would be associated with the need for a higher level of postextubation respiratory support.

\section{Methods}

The Institutional Review Board at Duke University Medical Center approved this study, including a waiver of

\footnotetext{
Supplementary material related to this paper is available at http://www. rcjournal.com.

Correspondence: Jonathan A Gehlbach MD, The Children's Hospital of Illinois at OSF St. Francis Medical Center, 530 NE Glen Oak Ave, Peoria, IL 61637.E-mail: jgehlb2@uic.edu.
}

DOI: $10.4187 /$ respcare. 07351

\section{QUICK LOOK}

\section{Current knowledge}

The dead space to tidal volume ratio $\left(\mathrm{V}_{\mathrm{D}} / \mathrm{V}_{\mathrm{T}}\right)$ is a quantitative measurement of respiratory dead space and has been reported to have prognostic value in a variety of disease states. In pediatrics, there have been 3 prior studies that yielded conflicting results when evaluating the association between $V_{\mathrm{D}} / \mathrm{V}_{\mathrm{T}}$ and extubation success, and only one of these studies was performed within the past 10 years.

\section{What this paper contributes to our knowledge}

This prospective, observational, cohort analysis is the largest clinical study to date to evaluate the association between $V_{D} / V_{T}$ and extubation success. $V_{D} / V_{T}$ was associated with the level of respiratory support provided immediately following extubation.

informed consent. We prospectively enrolled consecutive, invasively ventilated children $<18$ y old who were extubated in the pediatric multidisciplinary ICU and cardiac ICU at Duke Children's Hospital in Durham, North Carolina, from June 2016 through March 2017. We collected data using a combination of the electronic health record and a bedside data-collection sheet. Patients were excluded if they were extubated as part of withdrawal of life-sustaining care, received a tracheostomy at the time of extubation, or did not have an arterial blood gas (ABG) drawn within $12 \mathrm{~h}$ prior to extubation (ie, $\mathrm{P}_{\mathrm{aCO}_{2}}$ is required to determine $\mathrm{V}_{\mathrm{D}} / \mathrm{V}_{\mathrm{T}}$ ). We did not exclude patients on the basis of their disease processes. Subjects with multiple episodes of invasive ventilation were considered individually for each episode of extubation.

While receiving mechanical ventilation, subjects were managed with a respiratory therapist-driven mechanical ventilation protocol that included daily extubation readiness trials (ERT) in accordance with our institutional practice (see supplementary material at http://www.rcjournal.com). All children received invasive ventilation with AVEA ventilators (CareFusion, San Diego, California) while on conventional ventilator support, and all had heated humidifiers included in the ventilator circuit. To be considered for extubation, subjects had to pass an ERT, which consisted of 60$90 \mathrm{~min}$ of pressure support ventilation. The amount of pressure support provided (ie, $10 \mathrm{~cm} \mathrm{H}_{2} \mathrm{O}$ for $3.0-3.5-\mathrm{mm}$ tubes, $8 \mathrm{~cm} \mathrm{H}_{2} \mathrm{O}$ for $4.0-4.5$-mm tubes, and $6 \mathrm{~cm} \mathrm{H}_{2} \mathrm{O}$ for tubes $\geq 5.0 \mathrm{~mm}$ ) was set based on the size of the child. ${ }^{23}$ Subjects were considered to have failed their ERT if they developed one or more of the following: tachypnea (ie, breathing frequency $>60$ breaths/min for those $<6$ months 


\section{$\mathrm{V}_{\mathrm{D}} / \mathrm{V}_{\mathrm{T}}$ AND Postextubation Respiratory SuPPORT In CHILDRen}

old, breathing frequency $>45$ breaths/min for those 6-24 months old, breathing frequency $>40$ breaths/min for those who were 25-60 months old, or breathing frequency $>35$ breaths/min for older children), $\mathrm{V}_{\mathrm{T}}<5 \mathrm{~mL} / \mathrm{kg}$, or hypoxemia requiring $\mathrm{F}_{\mathrm{IO}_{2}}>0.5$. Additional findings, such as unexplained tachycardia during the ERT, were subjectively considered by the clinical team when deciding whether to proceed with extubation. Extubation was considered appropriate if the following conditions were met: passed ERT with adequate gas exchange, minimal sedation requirements, presence of cough and gag reflexes, and the presence of a leak around the endotracheal tube with the cuff deflated. The absence of a leak was not a contraindication to extubation, as routine practice in these instances is to proceed with extubation while administering 24-48 h of systemic corticosteroids to treat airway inflammation. The mechanical ventilation protocol used at our institution suggested an additional extubation criterion of $\mathrm{V}_{\mathrm{D}} / \mathrm{V}_{\mathrm{T}}$ $<0.6$, although the procedure also states that extubation could be considered at higher values (eg, if noninvasive ventilation was to be used after extubation). The ultimate decision to extubate was made at the discretion of the attending physician in conjunction with the clinical team.

Following extubation, clinical management continued according to standard practice. Support at extubation was determined by the care team under the supervision of the attending physician and was based on various factors such as radiographic evidence of disease, anticipated work of breathing after extubation, $\mathrm{F}_{\mathrm{IO}_{2}}$, baseline chronic lung disease, and duration of intubation. Because this was an observational study, we did not prescribe a formal protocol for respiratory support following extubation. HFNC was managed by the provider team, and CPAP and bi-level positive airway pressure (BPAP) were managed per the respiratory therapist-driven protocol, although transition from one mode to another required discussion with a physician or advanced practice nurse practitioner. The decision to escalate support was based on the clinical care team's assessment of work of breathing (eg, tachypnea, nasal flaring, accessory muscle use), hypoxemia, hypoventilation, or hemodynamic instability.

he primary end point for this study was extubation success, defined as avoiding re-intubation for $48 \mathrm{~h}$ after extubation. Secondary end points were planned support on extubation and escalation in support within $48 \mathrm{~h}$ after extubation. Low support was defined a priori as room air (ie, no respiratory support) or nasal cannula, whereas high support was defined as HFNC (defined as flow titrated to meet subjects' inspiratory demand and the $\mathrm{S}_{\mathrm{pO}_{2}}$ goal per clinical policy), CPAP, or BPAP. Escalation in support was defined as re-intubation, transition from low to high support, or from HFNC to CPAP or BPAP. Use of a helium-oxygen mixture for postextubation stridor was not tracked as part of this study.

\section{Data Collection}

We collected demographic data on each subject, including age, gender, race, diagnosis, ICU in which the subject was extubated, and duration of invasive ventilation prior to extubation. Age was recorded in years, rounded to the nearest month for those $<2$ y old. We categorized indications for invasive ventilation as pulmonary disease, cardiovascular disease, hemodynamic instability, operative/procedural, neurologic impairment, or upper-airway obstruction (including stridor). The same categorizations were used to stratify cause of extubation failure. Subjects were not limited to a single indication (eg, a subject who remained intubated postoperatively for a single-ventricle palliation procedure would have been included in the cardiovascular disease and operative/procedural groups). We also noted presence of baseline pulmonary disease and cyanotic congenital heart disease, when present.

Per standard clinical practice, daily (at minimum) $\mathrm{V}_{\mathrm{D}} / \mathrm{V}_{\mathrm{T}}$ measurements were obtained with each morning $\mathrm{ABG}$, excluding days in which subjects required extracorporeal membranous oxygenation or high-frequency ventilation. Additional $V_{D} / V_{T}$ measurements were obtained at the discretion of the clinical team. For each $\mathrm{V}_{\mathrm{D}} / \mathrm{V}_{\mathrm{T}}$ recorded, we documented the ventilator settings at the time the $\mathrm{ABG}$ was obtained: ventilator mode, set frequency, total peak inspiratory pressure, PEEP, pressure support, and $\mathrm{F}_{\mathrm{IO}_{2}}$. Per unit policy, targeted exhaled $\mathrm{V}_{\mathrm{T}}$ was $5-8 \mathrm{~mL} / \mathrm{kg}$ of ideal body weight.

Respironics NM3 respiratory monitors (Philips Healthcare, Eindhoven, Netherlands) were used to calculate $V_{D} / V_{T}$ values. The monitors utilize mainstream capnography at the endotracheal tube Y-piece to measure single-breath, real-time, mixed, expired $\mathrm{CO}_{2}$ concentration $\left(\mathrm{P}_{\overline{\mathrm{E}} \mathrm{CO}_{2}}\right)$, so named because it represents the concentration of $\mathrm{CO}_{2}$ exhaled from a mixture of large airways (physiologic dead space) and alveolar space. The monitors then use the subject's $\mathrm{P}_{\mathrm{aCO}}$ (obtained via ABG and manually entered into the monitor) to calculate the $V_{D} / V_{T}$ using the Enghoff modification of the Bohr equation: $\left(\mathrm{P}_{\mathrm{aCO}}-\mathrm{P}_{\overline{\mathrm{E} C O}_{2}}\right) / \mathrm{P}_{\mathrm{aCO}_{2}}{ }^{24}$ When technical issues precluded automated determination of $\mathrm{V}_{\mathrm{D}} / \mathrm{V}_{\mathrm{T}}$ values using the NM3 monitor, a small percentage were calculated manually using the same equation and a value for $\mathrm{P}_{\overline{\mathrm{E}}_{\mathrm{CO}}}$ that was pulled directly from the monitor at the coinciding time. Final $V_{D} / V_{T}$ refers to the last $\mathrm{V}_{\mathrm{D}} / \mathrm{V}_{\mathrm{T}}$ obtained before extubation; initial $\mathrm{V}_{\mathrm{D}} / \mathrm{V}_{\mathrm{T}}$ is the first $\mathrm{V}_{\mathrm{D}} / \mathrm{V}_{\mathrm{T}}$ obtained after intubation; mean $\mathrm{V}_{\mathrm{D}} / \mathrm{V}_{\mathrm{T}}$ is the average of all $\mathrm{V}_{\mathrm{D}} / \mathrm{V}_{\mathrm{T}}$ values during a subject's course of invasive mechanical ventilation; and peak $\mathrm{V}_{\mathrm{D}} / \mathrm{V}_{\mathrm{T}}$ is the maximum $V_{D} / V_{T}$ obtained during a subject's ventilator course. 
$\mathrm{V}_{\mathrm{D}} / \mathrm{V}_{\mathrm{T}}$ ANd Postextubation Respiratory Support in ChildRen

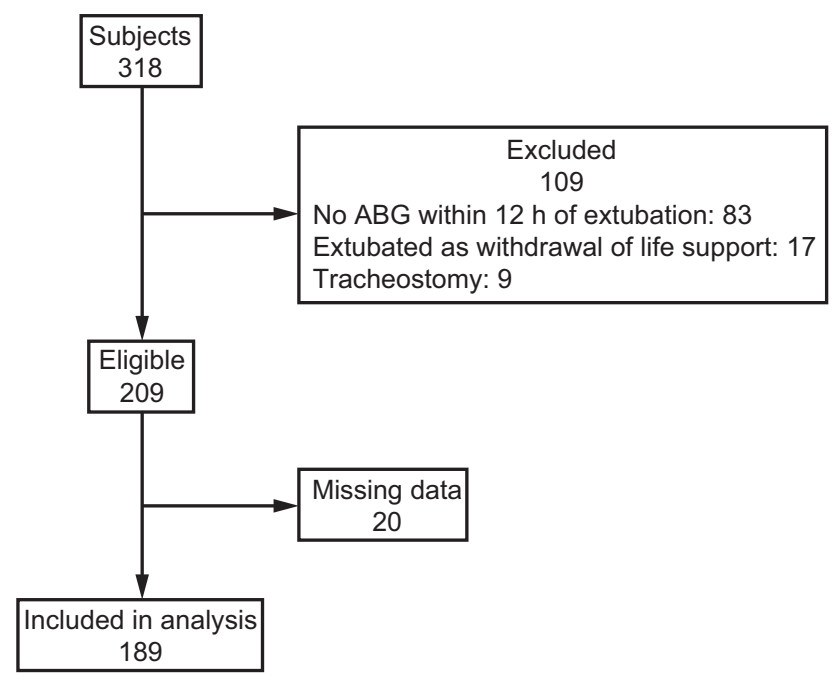

Fig. 1. Flow chart of subject enrollment. $A B G=$ arterial blood gas analysis.

\section{Data Analysis}

We used count and percentage or median and interquartile range (IQR) to describe categorical and continuous study variables, respectively. We compared the distribution of study variables among subjects who met or did not meet the primary and secondary end points using the Fisher exact or chi-square tests of association. We performed multivariable logistic regression analysis to evaluate the association between final $\mathrm{V}_{\mathrm{D}} / \mathrm{V}_{\mathrm{T}}$ prior to extubation and extubation failure, controlling for duration of intubation, presence of cyanotic congenital heart disease, and postnatal age. We used Stata 14.1 (StataCorp, College Station, Texas) to conduct all statistical analyses; $P<.05$ was considered statistically significant.

\section{Results}

We enrolled 318 children in the study. After excluding 109 subjects based on our aforementioned criteria and 20 for whom we had incomplete data, we analyzed 189 subjects (Fig. 1). The following indications for invasive mechanical ventilation were present: cardiovascular disease, $108(57 \%)$ subjects; operative/procedural, 102 (54\%) subjects; hemodynamic instability, 52 (28\%) subjects; pulmonary disease, 51 (27\%) subjects; neurologic impairment, 32 (17\%) subjects; and upper-airway obstruction, 4 (2\%) subjects. The pre-extubation characteristics are summarized in Table 1. The median (IQR) age was 0.42 y $(0.08-3.0)$. One hundred seven $(56 \%)$ children were males. Eighty-one $(43 \%)$ subjects were extubated in the pediatric multidisciplinary ICU (as opposed to the pediatric cardiac ICU), and $44(23 \%)$ subjects had cyanotic congenital heart disease. Six (3\%) subjects were extubated inadvertently. The
Table 1. Baseline Subject Characteristics at Time of Extubation

\begin{tabular}{|c|c|c|c|}
\hline Variable & $\begin{array}{l}\text { Successful } \\
\text { Extubation }\end{array}$ & $\begin{array}{l}\text { Failed } \\
\text { Extubation }\end{array}$ & $P$ \\
\hline Age, y & $0.33(0.08-3.0)$ & $1.25(0-6)$ & .87 \\
\hline Race & & & .64 \\
\hline $\begin{array}{l}\text { American Indian/Alaskan } \\
\text { Native }\end{array}$ & $2(1)$ & 0 & \\
\hline Asian & $6(4)$ & $2(9)$ & \\
\hline Black/African-American & $40(24)$ & $8(35)$ & \\
\hline Caucasian/White & $87(52)$ & $12(52)$ & \\
\hline$>1$ race & $5(3)$ & 0 & \\
\hline Unknown/unspecified & $9(5)$ & 0 & \\
\hline Other & $17(10)$ & $1(4)$ & \\
\hline Male & $94(57)$ & $13(57)$ & .58 \\
\hline PICU (vs. PCICU) & $69(42)$ & $12(52)$ & .23 \\
\hline $\begin{array}{l}\text { Cyanotic congenital heart } \\
\text { disease }\end{array}$ & $35(21)$ & $9(39)$ & .054 \\
\hline $\begin{array}{c}\text { Duration of invasive } \\
\text { ventilation, } h\end{array}$ & $78(29-170)$ & $111(46-310)$ & .059 \\
\hline Inadvertent extubation & $3(2)$ & $3(13)$ & .03 \\
\hline \multicolumn{4}{|c|}{$\begin{array}{l}\text { Data are presented as } n(\%) \text { or median (interquartile range). Successful extubation: } n=166 \text {; } \\
\text { Failed extubation: } n=23 \text {. } \\
\text { PICU = pediatric (multidisciplinary) ICU } \\
\text { PCICU = pediatric cardiac ICU }\end{array}$} \\
\hline
\end{tabular}

median (IQR) duration of invasive ventilation prior to attempted extubation was $80 \mathrm{~h}$ (31-173). Average ventilator support at the time the final pre-extubation $\mathrm{V}_{\mathrm{D}} / \mathrm{V}_{\mathrm{T}}$ was obtained was inspiratory pressure $12 \pm 2 \mathrm{~cm} \mathrm{H}_{2} \mathrm{O}$, PEEP $5 \pm 1 \mathrm{~cm} \mathrm{H}_{2} \mathrm{O}$, pressure support $10 \pm 2 \mathrm{~cm} \mathrm{H}_{2} \mathrm{O}$, set frequency $18 \pm 5$ breaths/min, and $\mathrm{F}_{\mathrm{IO}_{2}} 0.29 \pm 0.09$. The mode of mechanical ventilation when the final $V_{D} / V_{T}$ was obtained was pressure support ventilation (97 subjects, $51.3 \%$ ) or pressure control intermittent mandatory ventilation ( 86 subjects, $45.5 \%$ ) for the majority of subjects, while a significantly smaller number were supported with pressure-regulated volume control ventilation (3 subjects, $1.6 \%$ ) or continuous mandatory ventilation (1 subject, $0.5 \%$ ) (data not available for 2 subjects).

Twenty-three subjects (12\%) were re-intubated for the following reasons: 11 (48\%) for cardiovascular disease, $8(35 \%)$ for hemodynamic instability, $6(26 \%)$ for operative/procedural, 5 (22\%) for pulmonary disease, and 3 $(13 \%)$ each for neurologic impairment and upper-airway obstruction. Those who were successfully extubated had similar final pre-extubation $\mathrm{V}_{\mathrm{D}} / \mathrm{V}_{\mathrm{T}}$ to those who failed extubation, with a median (IQR) of 0.28 $(0.20-0.37)$ vs $0.29(0.21-0.33)$, respectively $(P=.87)$ (Figure 2). Similarly, there were no significant differences between mean $\mathrm{V}_{\mathrm{D}} / \mathrm{V}_{\mathrm{T}}(0.29$ [IQR $0.22-0.37$ ] vs 0.31 [IQR 0.24-0.37], $P=.49)$ and peak $\mathrm{V}_{\mathrm{D}} / \mathrm{V}_{\mathrm{T}}(0.37$ [IQR $0.27-0.45$ ] vs 0.42 [IQR $0.33-0.45$ ],$P=.15$ ) during the course of invasive ventilation. Those who failed extubation had slightly higher initial $V_{D} / V_{T}$ than those who 


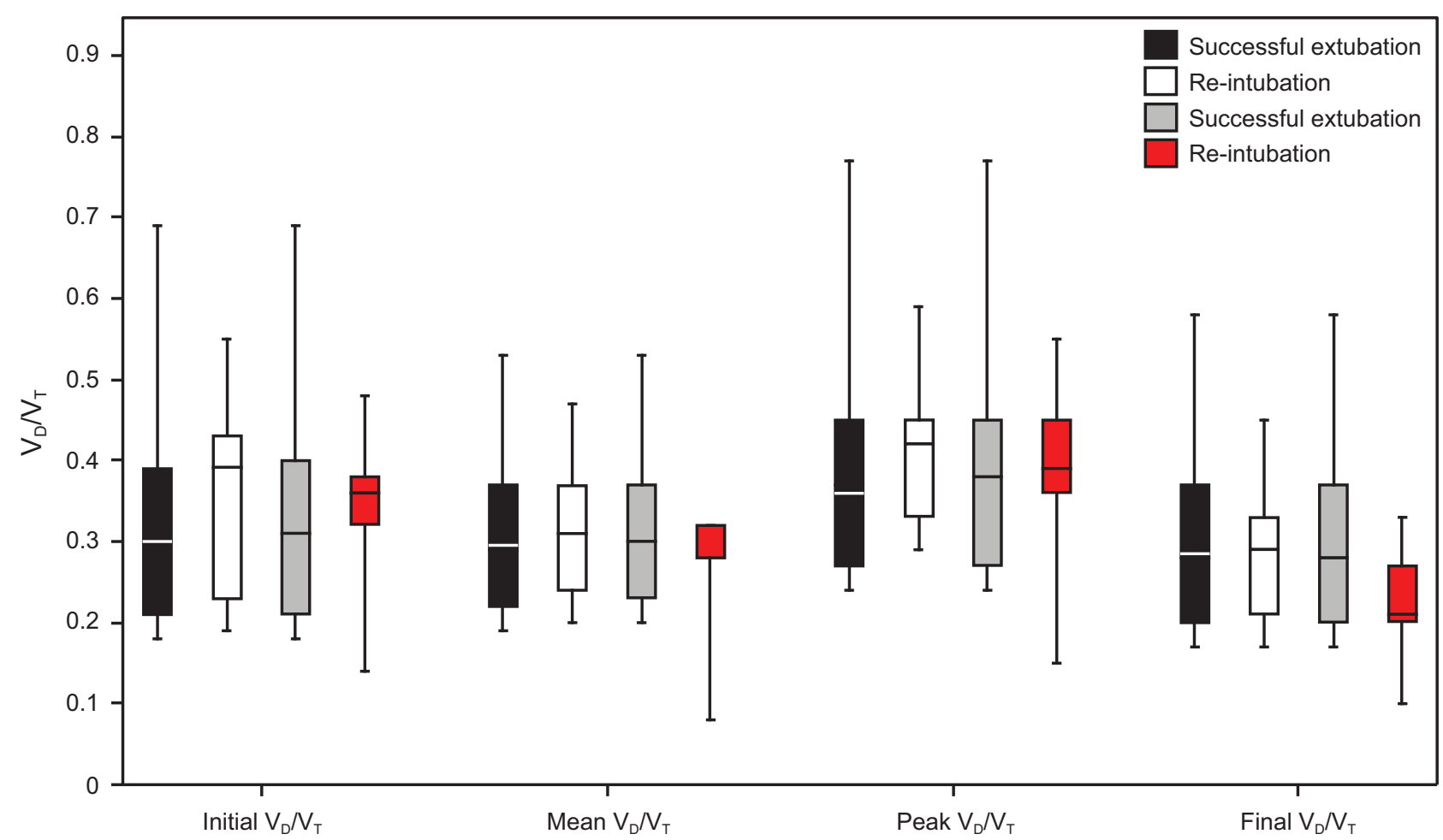

Fig. 2. Differences in the dead space to tidal volume $\left(V_{D} / V_{T}\right)$ between those who were extubated successfully and those who failed extubation. Black and white boxes represent all subjects, while gray and red boxes denote extubation outcome due to a pulmonary cause.

Table 2. Planned Respiratory Support Upon Extubation

\begin{tabular}{lccc}
\hline \hline Planned Extubation Support $(\%)$ & $\begin{array}{c}\text { Successful } \\
\text { Extubation }\end{array}$ & $\begin{array}{c}\text { Failed } \\
\text { Extubation }\end{array}$ & $P$ \\
\hline Room air & $27(16)$ & $3(14)$ & .62 \\
Nasal cannula & $41(25)$ & $3(14)$ & \\
High-flow nasal cannula & $87(52)$ & $14(64)$ & \\
CPAP & $1(1)$ & $0(0)$ & \\
Bi-level positive airway & $10(6)$ & $2(9)$ & \\
$\quad$ pressure & & &
\end{tabular}

$\overline{\text { Data are presented as } n}(\%)$. Successful extubation: $n=166$; Failed extubation: $n=22$

successfully extubated, although this association did not meet statistical significance $(0.30$ [IQR $0.21-0.39$ ] vs 0.39 [IQR $0.23-0.43$ ] $P=.067$ ). Of the subjects who had upper-airway obstruction at the time of initial intubation, only 1 required an increase in respiratory support after extubation and was re-intubated. When we limited our analysis to compare only the 5 subjects who were re-intubated due to a pulmonary etiology versus those who were not (eg, excluding those with postextubation stridor), none of these parameters (eg, final $\mathrm{V}_{\mathrm{D}} / \mathrm{V}_{\mathrm{T}}$, mean $\mathrm{V}_{\mathrm{D}} / \mathrm{V}_{\mathrm{T}}$, peak $\mathrm{V}_{\mathrm{D}} / \mathrm{V}_{\mathrm{T}}$, initial $\mathrm{V}_{\mathrm{D}} / \mathrm{V}_{\mathrm{T}}$ ) reached statistical significance (Fig. 2).

Table 2 summarizes the planned respiratory support upon extubation for the study subjects. Of the 188 subjects initially supported with noninvasive support upon extubation, 114 (61\%) were extubated to high support. One subject who had been inadvertently extubated was immediately re-intubated and, therefore, did not have any planned postextubation support documented. As shown in Figure 3, those who were extubated to high support had higher final $V_{D} / V_{T}$ than those who were extubated to low support (0.32 [IQR $0.23-0.39$ vs 0.25 [IQR 0.16-0.30], $P<.001)$, mean $\mathrm{V}_{\mathrm{D}} / \mathrm{V}_{\mathrm{T}}(0.33$ [IQR $0.25-0.40$ ] vs 0.26 [IQR $0.20-0.32$ ],$P<.001$ ), peak $\mathrm{V}_{\mathrm{D}} /$ $\mathrm{V}_{\mathrm{T}}(0.41$ [IQR $0.32-0.51$ ] vs 0.31 [IQR $0.22-0.39$ ], $P<$ $.001)$, and initial $\mathrm{V}_{\mathrm{D}} / \mathrm{V}_{\mathrm{T}}(0.34$ [IQR $0.22-0.43$ ] vs 0.28 [IQR 0.20-0.37], $P=.005$ ).

Forty-four (23\%) subjects required an escalation of support after extubation. There were no significant associations between requiring an escalation in support and final $\mathrm{V}_{\mathrm{D}} / \mathrm{V}_{\mathrm{T}}$ (0.31 [IQR 0.22-0.38] vs 0.28 [IQR 0.20-0.36], $P=.44$ ), mean $\mathrm{V}_{\mathrm{D}} / \mathrm{V}_{\mathrm{T}}(0.31$ [IQR $0.22-0.39$ ] vs 0.29 [IQR 0.23 0.36 ], $P=.38)$, peak $\mathrm{V}_{\mathrm{D}} / \mathrm{V}_{\mathrm{T}}(0.40$ [IQR $0.31-0.45$ ] vs 0.36 [IQR 0.27-0.45], $P=.19)$, or initial $\mathrm{V}_{\mathrm{D}} / \mathrm{V}_{\mathrm{T}}(0.35$ [IQR $0.20-0.42$ ] vs 0.29 [IQR $0.21-0.39$ ], $P=.36$ ). These relationships are displayed in Figure 4.

\section{Multivariate Analysis}

In multivariate analysis, the adjusted odds ratio for increased final $\mathrm{V}_{\mathrm{D}} / \mathrm{V}_{\mathrm{T}}$ and extubation failure was 0.11 (95\% 


\section{$\mathrm{V}_{\mathrm{D}} / \mathrm{V}_{\mathrm{T}}$ AND PosteXtubation RespiRatory Support in ChildRen}

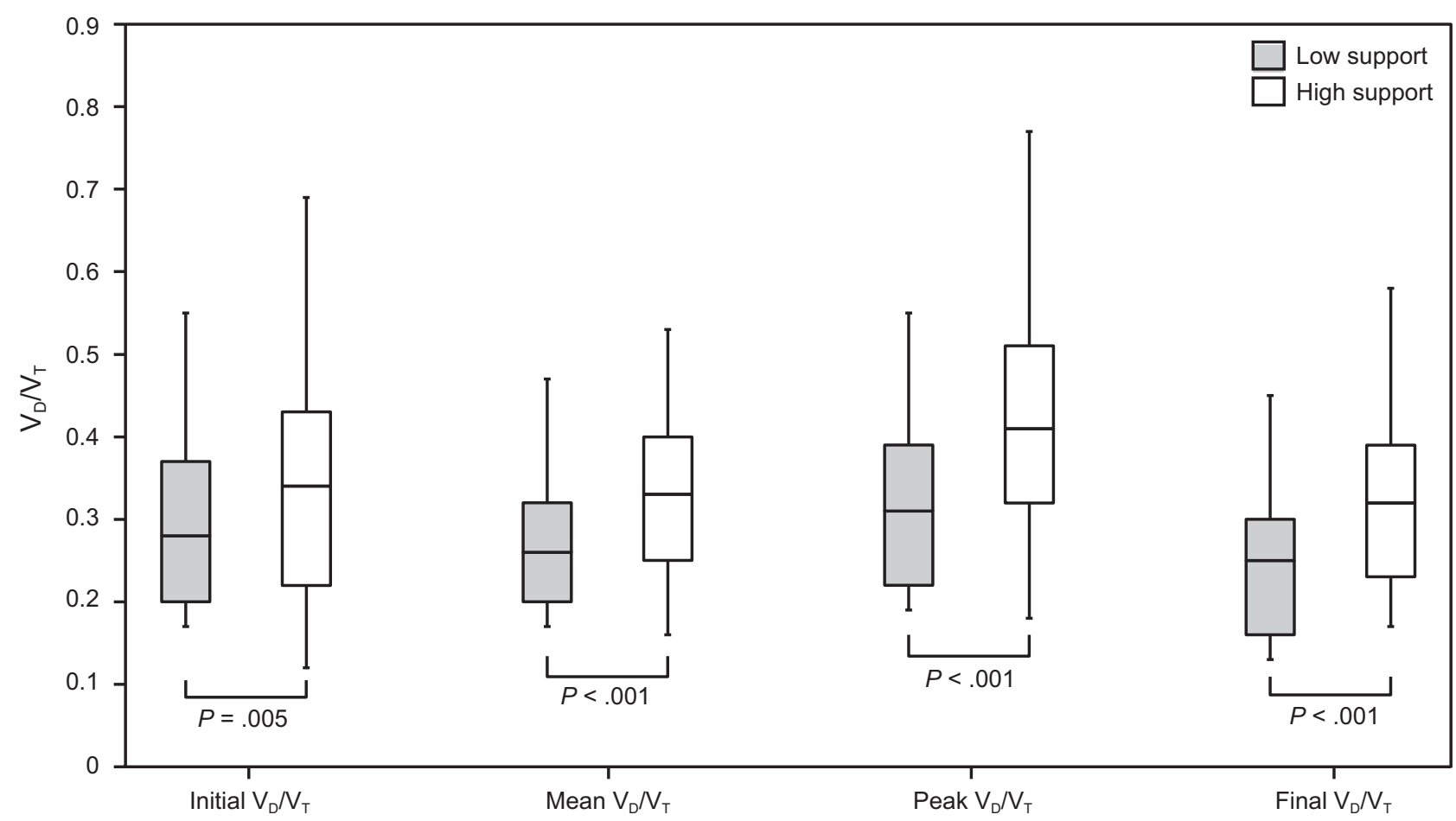

Fig. 3. Differences in the ratio of dead space to tidal volume $\left(V_{D} / V_{T}\right)$ between those requiring low support and high support on extubation. Low support refers to room air or nasal cannula; high support refers to high-flow nasal cannula, CPAP, or bi-level positive airway pressure.

$\mathrm{CI}<0.01-7.34, P=.30$ ) when controlling for intubation duration, presence of cyanotic congenital heart disease, and age. For our secondary analyses, the adjusted odds ratio for an increase in $\mathrm{V}_{\mathrm{D}} / \mathrm{V}_{\mathrm{T}}$ of $\geq 0.1$ and high support upon extubation was 1.63 (95\% CI $1.18-2.24, P=.003)$; and the adjusted odds ratio for an increase in final $\mathrm{V}_{\mathrm{D}} / \mathrm{V}_{\mathrm{T}}$ of 0.1 and escalation in support after extubation was 1.01 (95\% CI $0.74-1.38, P=.93$ ), controlling for these same factors.

\section{Discussion}

In this prospective, observational, cohort study, we performed the largest analysis to date of the association between $\mathrm{V}_{\mathrm{D}} / \mathrm{V}_{\mathrm{T}}$ and extubation success. In adjusted analysis, the final pre-extubation $V_{D} / V_{T}$ was not associated with an increased risk of re-intubation when controlling for age, presence of cyanotic congenital heart disease, and duration of intubation. We did, however, find a significant association between final $V_{D} / V_{T}$ and initial noninvasive respiratory support selected by the clinical team at the time of extubation.

Because $V_{D} / V_{T}$ is a quantitative measure of physiologic dead space, its association with extubation failure would only pertain to those at risk of failing extubation from a pulmonary etiology (ie, those with increased alveolar dead space). We would not expect $V_{D} / V_{T}$ to be associated with failure from other causes, such as upper-airway obstruction, which is the most common cause of extubation failure in children. ${ }^{1,45}$ However, when we limited our analysis to examine the 5 subjects who failed extubation due to a primarily pulmonary cause, the findings were unchanged from the analyses that included all causes for extubation failure.

Prior studies on this topic have yielded conflicting results. In a 2000 study of 45 subjects, Hubble et al ${ }^{19}$ reported a positive association between $\mathrm{V}_{\mathrm{D}} / \mathrm{V}_{\mathrm{T}}>0.65$ and risk for extubation failure, whereas a $\mathrm{V}_{\mathrm{D}} / \mathrm{V}_{\mathrm{T}} \leq 0.50$ was predictive of extubation success. Riou et $\mathrm{a}^{20}$ noted a similar association in a 2012 study of 42 children, albeit with a different $V_{\mathrm{D}} / \mathrm{V}_{\mathrm{T}}$ threshold. They reported that subjects with $\mathrm{V}_{\mathrm{D}} / \mathrm{V}_{\mathrm{T}} \leq 0.55$ were significantly more likely to extubate without noninvasive support, which is consistent with our finding that those with higher $V_{D} / V_{T}$ received noninvasive support upon extubation. In a recent retrospective study of children following surgical repair of congenital heart disease, Devor et $\mathrm{al}^{22}$ reported that $\mathrm{V}_{\mathrm{D}} / \mathrm{V}_{\mathrm{T}}>0.5$ was associated with extubation failure in 61 children with 2-ventricle physiology but was not predictive for children with single-ventricle physiology. Additionally, Bousso et $\mathrm{al}^{21}$ reported that $\mathrm{V}_{\mathrm{D}} / \mathrm{V}_{\mathrm{T}}>$ 0.65 was not predictive of re-intubation or of a need for noninvasive support following extubation in a study of 86 children.

Based on the studies by Hubble et $\mathrm{al}^{19}$ and Riou et $\mathrm{al},{ }^{20}$ the $\mathrm{V}_{\mathrm{D}} / \mathrm{V}_{\mathrm{T}}$ threshold that appears to be associated with a higher risk of extubation failure is $0.50-0.55$. In this 


\section{$\mathrm{V}_{\mathrm{D}} / \mathrm{V}_{\mathrm{T}}$ AND PosteXtubation RespiRatory Support in CHILdREN}

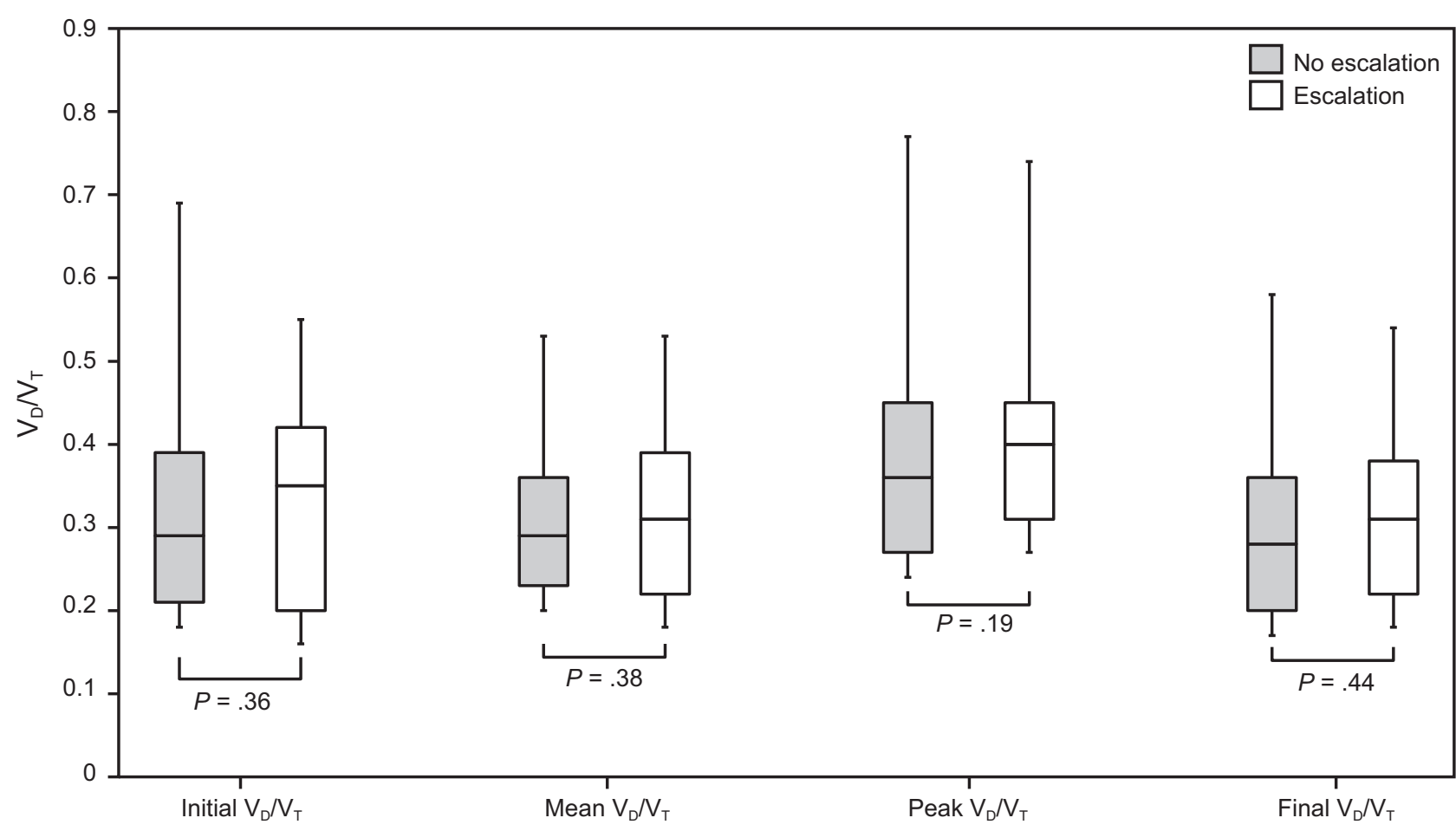

Fig. 4. Differences in the ratio of dead space to tidal volume $\left(V_{D} / V_{T}\right)$ between those who were extubated without escalation of support and those who required an escalation in support after extubation. Escalation refers to re-intubation, transition from low support (ie, room air or nasal cannula) to high support (ie, high-flow nasal cannula, CPAP, or bi-level positive airway pressure), or transition from high-flow nasal cannula to noninvasive ventilation.

context, it is important to highlight that the 95th percentile for pre-extubation $\mathrm{V}_{\mathrm{D}} / \mathrm{V}_{\mathrm{T}}$ in our study was 0.53 , indicating that a large majority of subjects we extubated fell below the increased risk threshold. This limitation of our study was likely driven by an institutional bias, as one of the earlier studies showing an association between $\mathrm{V}_{\mathrm{D}} / \mathrm{V}_{\mathrm{T}}$ and extubation failure was performed at our center. ${ }^{19}$ Furthermore, the use of ERTs at our institution may have also limited attempts to extubate subjects with significant pulmonary pathology and higher $V_{D} / V_{T}$, which is supported by the relatively low average ventilator settings in our subjects when the final $V_{D} / V_{T}$ values were obtained.

Although ours is still a relatively small study, one of its strengths is the number of subjects in comparison to the existing literature. We included a total of 189 subjects, which is more than twice as large as any prior study to evaluate $V_{D} / V_{T}$ and extubation failure in pediatrics. Our study had fewer exclusion criteria than previous studies, but this was deliberate because one of our goals was to assess the utility of $\mathrm{V}_{\mathrm{D}} / \mathrm{V}_{\mathrm{T}}$ as a global screening tool for extubation readiness regardless of indication for intubation, given that alveolar dead space can occur in patients intubated for nonpulmonary indications.

We intentionally included subjects with underlying chronic lung disease, given that alveolar dead space may affect successful extubation in these patients. However, the inclusion of these subjects may have confounded our results because it is possible that a subject's underlying lung disease (and baseline respiratory support) affected the clinical team's decision on timing of extubation as well as support after extubation. We also included subjects with cyanotic congenital heart disease in whom $\mathrm{V}_{\mathrm{D}} / \mathrm{V}_{\mathrm{T}}$ may be elevated by variable amounts of intracardiac shunting because blood passing directly from venous to arterial circulations does so without a chance for $\mathrm{CO}_{2}$ elimination in the lungs. ${ }^{18}$ Although $\mathrm{V}_{\mathrm{D}} / \mathrm{V}_{\mathrm{T}}$ does not differentiate between pulmonary dead space and intracardiac shunting, we opted to include both 2-ventricle and single-ventricle subjects with congenital heart disease given that an increased amount of dead space (even if impacted by intracardiac shunting) might impact the readiness for these children to successfully extubate.

An additional possible limitation is our decision to include subjects who had multiple episodes of invasive mechanical ventilation to capture the potential changes in physiology (and dead space) that can occur with each separate course of intubation. We also included inadvertent extubations because we strove to evaluate whether those with lower $V_{\mathrm{D}} / \mathrm{V}_{\mathrm{T}}$ would be more likely to tolerate extubation than those with high $\mathrm{V}_{\mathrm{D}} / \mathrm{V}_{\mathrm{T}}$ in the event of accidental endotracheal tube dislodgement (although these subjects may have other risks for failure, such as persisting effects of sedation). 


\section{$\mathrm{V}_{\mathrm{D}} / \mathrm{V}_{\mathrm{T}}$ AND Postextubation Respiratory SuPPORT In CHILDRen}

Although we did not see an association between $\mathrm{V}_{\mathrm{D}} / \mathrm{V}_{\mathrm{T}}$ and extubation success, we did find that increased $\mathrm{V}_{\mathrm{D}} / \mathrm{V}_{\mathrm{T}}$ was associated with providers' selection of a higher level of postextubation respiratory support. There have been significant advancements in recent years that have improved the ability to manage patients noninvasively, as several relatively recent studies (of both adult ${ }^{25-27}$ and pediatric ${ }^{28}$ subjects) have shown benefit of early extubation to noninvasive support. Perhaps for this reason it is not entirely surprising that more than half of all subjects were extubated to HFNC, although this highly prevalent use of HFNC is a limitation of our study. Although it is premature to conclude that noninvasive support can help successfully bridge those with high $\mathrm{V}_{\mathrm{D}} / \mathrm{V}_{\mathrm{T}}$ through extubation, further studies should seek to evaluate extubation criteria in a contemporary era of advanced noninvasive support.

There were other limitations to this study that may affect the generalizability of the results. By using only arterial specimens for blood gas analysis, we optimized the accuracy of our $\mathrm{V}_{\mathrm{D}} / \mathrm{V}_{\mathrm{T}}$ values but may have, in turn, sacrificed the generalizability of the results to those who require an arterial sample from an arterial puncture or to those with arterial catheters, which may select for a sicker cohort of invasively ventilated patients. In addition, the observational design of the study leaves it open to potential biases. The management of the subjects, including timing of extubation, planned support on extubation, and decision to escalate support or re-intubate following extubation, was at the discretion of the clinical team. Because the providers were not blinded to the $\mathrm{V}_{\mathrm{D}} / \mathrm{V}_{\mathrm{T}}$ data, clinician knowledge of the subjects' $V_{\mathrm{D}} / \mathrm{V}_{\mathrm{T}}$ may have affected the decision for postextubation support. Therefore, it remains unclear whether $\mathrm{V}_{\mathrm{D}} / \mathrm{V}_{\mathrm{T}}$ can be used to guide determination of which patients require noninvasive support at extubation.

Our multivariable analysis controlled for age, the presence of cyanotic congenital heart disease, and the duration of intubation; however, it is possible there were other confounding variables we could not control. The multivariable analysis was limited by our relatively limited sample size.

We considered transition from HFNC to either CPAP or BPAP an escalation in support because transition from noninvasive ventilation to HFNC rarely occurs in our practice. The design of the study may have also had implications because 83 subjects were excluded due to the lack of an ABG within $12 \mathrm{~h}$ of extubation. Since most blood gases are obtained in our ICUs around 4:00 AM, there may have been a selective exclusion of subjects extubated in the evening (ie, $>12 \mathrm{~h}$ later).

Finally, this study was performed at a single center, limiting the generalizability of the results. While our re-intubation rate $(12 \%)$ is within the range of what has been reported, ${ }^{1-7}$ the ideal re-intubation rate in pediatrics is unknown and likely differs based on the needs of individual centers, units, and patient populations.

\section{Conclusions}

We found no significant relationship between $\mathrm{V}_{\mathrm{D}} / \mathrm{V}_{\mathrm{T}}$ and extubation success, but we did observe that higher $\mathrm{V}_{\mathrm{D}} / \mathrm{V}_{\mathrm{T}}$ was associated with higher planned respiratory support on extubation. An elevated $\mathrm{V}_{\mathrm{D}} / \mathrm{V}_{\mathrm{T}}$ at the time of extubation may serve to alert clinicians of patients who are at increased risk of respiratory distress/failure following extubation.

\section{REFERENCES}

1. Edmunds S, Weiss I, Harrison R. Extubation failure in a large pediatric ICU population. Chest 2001;119(3):897-900.

2. Farias JA, Retta A, Alia I, Olazarri F, Esteban A, Golubicki A, et al. A comparison of two methods to perform a breathing trial before extubation in pediatric intensive care patients. Intensive Care Med 2001;27 (10):1649-1654.

3. Farias JA, Alía I, Retta A, Olazarri F, Fernández A, Esteban A, et al. An evaluation of extubation failure predictors in mechanically ventilated infants and children. Intensive Care Med 2002;28(6):752-757.

4. Kurachek SC, Newth CJ, Quasney MW, Rice T, Sachdeva RC, Patel $\mathrm{NR}$, et al. Extubation failure in pediatric intensive care: a multiplecenter study of risk factors and outcomes. Crit Care Med 2003;31 (11):2657-2664.

5. Baisch SD, Wheeler WB, Kurachek SC, Cornfield DN. Extubation failure in pediatric intensive care incidence and outcomes. Pediatr Crit Care Med 2005;6(3):312-318.

6. Gaies M, Tabbutt S, Schwartz SM, Bird GL, Alten JA, Shekerdemian LS, et al. Clinical epidemiology of extubation failure in the pediatric cardiac ICU: a report from the Pediatric Cardiac Critical Care Consortium. Pediatr Crit Care Med 2015;16(9):837-845.

7. Khemani RG, Sekayan T, Hotz J, Flink RC, Rafferty GF, Iyer N, et al. Risk factors for pediatric extubation failure: the importance of respiratory muscle strength. Crit Care Med 2017;45(8):e798-e805.

8. González-Castro A, Suárez-Lopez V, Gómez-Marcos V, GonzálezFernandez C, Iglesias-Posadilla D, Burón-Mediavilla J, et al. Utility of the dead space fraction $(\mathrm{Vd} / \mathrm{Vt})$ as a predictor of extubation success. Med Intensiva 2011;35(9):529-538.

9. Ozyılmaz E, Aydoğdu M, Gürsel G. The role of physiologic dead space measurement in predicting extubation success. Tuberk Toraks 2010;58(2):154-161.

10. Kallet RH, Alonso JA, Pittet JF, Matthay MA. Prognostic value of the pulmonary dead-space fraction during the first 6 days of acute respiratory distress syndrome. Respir Care 2004;49(9):1008-1014.

11. Nuckton TJ, Alonso JA, Kallet RH, Daniel BM, Pittet JF, Eisner MD, et al. Pulmonary dead-space fraction as a risk factor for death in the acute respiratory distress syndrome. N Engl J Med 2002;346 (17):1281-1286.

12. Raurich JM, Vilar M, Colomar A, Ibanez J, Ayestaran I, PerezBarcena J, et al. Prognostic value of the pulmonary dead-space fraction during the early and intermediate phases of acute respiratory distress syndrome. Respir Care 2010;55(3):282-287.

13. Kallet RH, Zhuo H, Liu KD, Calfee CS, Matthay MA, National Heart Lung and Blood Institute ARDS Network Investigators. The association between physiologic dead-space fraction and mortality in subjects with ARDS enrolled in a prospective multi-center clinical trial. Respir Care 2014;59(11):1611-1618.

14. Ashutosh K, Dev G, Steele D. Nonbronchodilator effects of pirbuterol and ipratropium in chronic obstructive pulmonary disease. Chest 1995; 107(1):173-178.

15. Arnold JH, Bower LK, Thompson JE. Respiratory deadspace measurements in neonates with congenital diaphragmatic hernia. Crit Care Med 1995;23(2):371-375. 


\section{$\mathrm{V}_{\mathrm{D}} / \mathrm{V}_{\mathrm{T}}$ AND Postextubation Respiratory SuPPORT In CHILDRen}

16. Coss-Bu JA, Walding DL, David YB, Jefferson LS. Dead space ventilation in critically ill children with lung injury. Chest 2003;123 (6):2050-2056.

17. Arnold JH, Thompson JE, Benjamin PK. Respiratory deadspace measurements in neonates during extracorporeal membrane oxygenation. Crit Care Med 1993;21(12):1895-1900.

18. Ong T, Stuart-Killion RB, Daniel BM, Presnell LB, Zhuo H, Matthay MA, et al. Higher pulmonary dead space may predict prolonged mechanical ventilation after cardiac surgery. Pediatr Pulmonol 2009;44 (5):457-463.

19. Hubble CL, Gentile MA, Tripp DS, Craig DM, Meliones JN, Cheifetz IM. Deadspace to tidal volume ratio predicts successful extubation in infants and children. Crit Care Med 2000;28(6):2034-2040.

20. Riou Y, Chaari W, Leteurtre S, Leclerc F. Predictive value of the physiological deadspace/tidal volume ratio in the weaning process of mechanical ventilation in children. J Pediatr (Rio J) 2012;88(3):217-221.

21. Bousso A, Ejzenberg B, Ventura AM, Fernandes JC, Fernandes IC, Góes PF, et al. Evaluation of the dead space to tidal volume ratio as a predictor of extubation failure. J Pediatr (Rio J) 2006;82(5):347-353.

22. Devor RL, Kang P, Wellnitz C, Nigro JJ, Velez DA, Willis BC. Pulmonary dead space fraction and extubation success in children after cardiac surgery. Pediatr Crit Care Med 2018;19(4):301-309.
23. Bock KR, Silver P, Rom M, Sagy M. Reduction in tracheal lumen due to endotracheal intubation and its calculated clinical significance. Chest 2000;118(2):468-472.

24. Bourgoin P, Baudin F, Brossier D, Emeriaud G, Wysocki M, Jouvet P. Assessment of Bohr and Enghoff dead space equations in mechanically ventilated children. Respir Care 2017;62(4):468-474.

25. Burns KE, Meade MO, Premji A, Adhikari NK. Noninvasive positivepressure ventilation as a weaning strategy for intubated adults with respiratory failure. Cochrane Database Syst Rev 2013;12:CD004127.

26. Hernández G, Vaquero C, González P, Subira C, Frutos-Vivar F, Rialp G, et al. Effect of postextubation high-flow nasal cannula vs conventional oxygen therapy on reintubation in low-risk patients: a randomized clinical trial. JAMA 2016;315(13):1354-1361.

27. Hernández G, Vaquero C, Colinas L, Cuena R, González P, Canabal A, et al. Effect of postextubation high-flow nasal cannula vs noninvasive ventilation on reintubation and postextubation respiratory failure in high-risk patients: a randomized clinical trial. JAMA 2016;316 (15):1565-1574.

28. Mayordomo-Colunga J, Medina A, Rey C, Concha A, Menéndez S, Los Arcos M, et al. Non invasive ventilation after extubation in paediatric patients: a preliminary study. BMC Pediatr 2010;10:29. 